\title{
Impact of different definitions of clear-sky flux on the determination of longwave cloud radiative forcing: NICAM simulation results
}

\author{
B. J. Sohn ${ }^{1}$, T. Nakajima ${ }^{2}$, M. Satoh ${ }^{2}$, and H.-S. Jang ${ }^{1}$ \\ ${ }^{1}$ School of Earth and Environmental Sciences, Seoul National University, Seoul, 151-747, Korea \\ ${ }^{2}$ Atmosphere and Ocean Research Institute, University of Tokyo, 5-1-5 Kashiwanoha, Kashiwa, Chiba, 277-8568, Japan
}

Received: 29 August 2010 - Published in Atmos. Chem. Phys. Discuss.: 24 September 2010

Revised: 29 November 2010 - Accepted: 30 November 2010 - Published: 8 December 2010

\begin{abstract}
Using one month of the cloud-resolving Nonhydrostatic Icosahedral Atmospheric Model (NICAM) simulations, we examined the impact of different definitions of clear-sky flux on the determination of longwave cloud radiative forcing (CRF). Because the satellite-like cloud-free composite preferentially samples drier conditions relative to the all-sky mean state, the conventional clear-sky flux calculation using the all-sky mean state in the model may represent a more humid atmospheric state in comparison to the cloudfree state. The drier bias is evident for the cloud-free composite in the NICAM simulations, causing an overestimation of the longwave CRF by about $10 \%$ compared to the NICAM simulated longwave CRF. Overall, water vapor contributions of up to $10 \%$ of the total longwave CRF should be taken account for making model-generated cloud forcing comparable to the satellite measurements.
\end{abstract}

\section{Introduction}

With the advent of satellite measurements, such as the Earth Radiation Budget Experiment (ERBE; Barkstrom et al., 1989) and Clouds and the Earth's Radiant Energy System (CERES; Wielicki et al., 1996), the influence of clouds on radiation (so-called cloud radiative forcing (CRF)) has been quantified. In this satellite approach, the CRF is determined by subtracting the composite of clear-sky radiation flux (i.e., cloud-free flux) from the all-sky measured flux (e.g., Ramanathan et al., 1989). The geographical distribu-

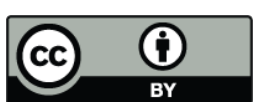

Correspondence to: B. J. Sohn

(sohn@snu.ac.kr) tion and temporal variability of satellite-measured CRF have been widely used for evaluating the performance of climate models and for understanding physical processes associated with clouds.

While it is important for models to reproduce the climatological distributions of the observed clear-sky radiation flux and associated cloud radiative forcing, caution should be taken because model-determined CRF may not be comparable to satellite estimates (Sohn and Robertson, 1993; Slingo et al., 1998; Allan and Ringer, 2003; Roca et al., 2005). These incompatible behaviors occur because, in the satellite approach, only clear-sky scenes are taken to calculate the clear-sky flux (i.e., cloud-free flux) while a modeling approach generally uses atmospheric conditions derived from model outputs representing the all-sky atmospheric state and assuming zero cloud cover. Because clouds form only over thermodynamically and dynamically favorable conditions, such as moisture convergences, atmospheric conditions used for the clear-sky composite in the satellite approach should not be same as those used for the model calculations of clearsky flux. Because of the different definitions of clear-sky flux employed by the satellite and modeling approaches, the CRFs are not necessarily the same even if satellite-estimated clear-sky flux and all-sky flux are exactly the same as those from the model.

These differences hold particularly true for longwave CRF over convectively active regions. It has been noted that the magnitudes of clear-sky flux difference (and thus CRF difference) can be as large as $15 \mathrm{Wm}^{-2}$ over convectively active tropical areas, which is mainly due to the upper tropospheric humidity (UTH) difference between clear-sky and all-sky atmospheres (Sohn et al., 2006; Sohn and Bennartz, 2008). These results are consistent with previous findings

Published by Copernicus Publications on behalf of the European Geosciences Union. 
suggesting that a sampling bias in satellite-based clear-sky measurements toward drier and more stable atmospheric conditions can cause about a $15 \mathrm{Wm}^{-2}$ difference over warm oceanic regions (Allan and Ringer, 2003).

A sampling similar to the one used for the satellite approach is desirable but has not been possible due to the crude spatial and temporal resolutions in the normal climate models. However, the recent development of a new global climate model, the cloud-resolving Nonhydrostatic Icosahedral Atmospheric Model (NICAM; Tomita and Satoh, 2004; Satoh et al., 2008), provides an opportunity to examine how cloud forcing is influenced by different definitions of the clear-sky flux in a global context. The model produces outputs in $1.5 \mathrm{~h}$ intervals ( 16 times per day) with a $7 \mathrm{~km}$ spatial resolution, allowing it not only to mimic the sampling adopted by a satellite approach, but also to cover diurnal variations. Using the NICAM simulations, we examine how satellite-based longwave CRF should be systematically different from modelgenerated longwave CRF.

\section{Methodology and NICAM simulation outputs}

In the satellite approach, only cloud-free pixels are taken to construct a clear-sky composite field. Conceptually different from the satellite approach, the modeling approach normally calculates clear-sky longwave fluxes diagnostically using the mean atmospheric state and setting the cloud amount to zero, even though the cloud amount is generally not zero. Because NICAM produces high resolution outputs with spatial and temporal resolutions that are comparable to those of geostationary satellites, it is possible to calculate the clear-sky flux by using only the cloud-free grids to mimic a satellite approach. The clear-sky flux obtained in this manner is referred to as "cloud-free" flux, differentiating it from the conventional model-based "clear-sky" flux, which is based on a radiative-transfer calculation with all-sky atmospheric conditions and an assumption of zero cloud cover.

In this study, we use one month (15 December 2006-15 January 2007) of NICAM global simulations with a spatial resolution of about $7 \mathrm{~km}$. Details of these simulations are found in Miura et al. (2007). In the NICAM simulations, profile data, such as temperature, water vapor, and wind are stored every six hours as instantaneous values in the original icosahedral grid data, and they are converted into equal latitude-longitude grid format (a total of $5120 \times 2560$ grid points over the globe). Non-profile data, such as cloud amount, outgoing longwave radiation (OLR), and total precipitable water (TPW), are stored every $90 \mathrm{~min}$, and they represent meteorological conditions in the $90 \mathrm{~min}$ prior to the stored time. Using the NICAM simulations, we examine how water vapor fields corresponding to clear-sky flux and cloud-free flux are different and we investigate how those differences force OLR changes at the top of the atmosphere (TOA).
Comparisons are made at intervals of $1^{\circ} \times 1^{\circ}$ latitudelongitude grid, with each cell containing about 200 grid points of $7 \mathrm{~km}$ resolution data. Constructing the cloud-free OLR and associated humidity profiles, cloud-free points are determined using the model-generated cloud amount present at the original grid-point level. Cloudy grids are defined by using $0.005 \mathrm{~g} \mathrm{~kg}^{-1}$ as a critical value of total condensate mixing ratio (Miura et al., 2005). Once the cloud-free points are determined from the six-hourly data, cloud-free OLR fluxes and water vapor profiles are constructed by taking their averages within a $1^{\circ} \times 1^{\circ}$ grid box. Because cloud-free and clear-sky fluxes and their associated water vapor profiles are obtained at each time step, monthly means for a $1^{\circ} \times 1^{\circ}$ grid box are calculated by taking the averages of the values of all the stored time steps over the one month period.

\section{Dry bias of cloud-free atmosphere in comparison to all-sky atmosphere}

Using the methodology described in Sect. 2, all-sky TPW, cloud-free TPW, all-sky UTH, and cloud-free UTH are calculated. In Fig. 1, one month (15 December 2006-15 January 2007) mean all-sky TPW, difference between cloud-free TPW and all-sky TPW (henceforth referred to as $\Delta \mathrm{TPW}_{\mathrm{f}}$ ), all-sky UTH, and difference between cloud-free UTH and all-sky UTH (henceforth referred to as $\Delta \mathrm{UTH}_{\mathrm{f}}$ ) are presented. Here UTH represents the mean relative humidity over the 200-500 hPa layer.

The geographic distributions of all-sky TPW and $\Delta \mathrm{TPW}_{\mathrm{f}}$ are shown in Fig. 1a and b, respectively. The difference $\left(\triangle \mathrm{TPW}_{\mathrm{f}}\right)$ map shows a general dry bias (negative values) of the TPW from a cloud-free sky. Drier biases larger than $5 \mathrm{~kg} \mathrm{~m}^{-2}$ are found over convectively active regions in the tropics and over mid-latitude storm tracks. In contrast, in subtropical subsidence areas dry bias is much smaller and the difference even turns to a moist bias (positive values) in some areas, such as the oceanic regions off the west coasts of South Africa, Australia, and California. Such positive biases over the cold ocean regions may be due to the fact that the large-scale subsidence (and thus prevailing dryness) over those regions is one major element of producing marine stratocumulus clouds. The general dry bias shown in the clearsky atmosphere is also consistent with a satellite observation study by Sohn and Bennartz (2008) that found drier biases of up to $3-5 \mathrm{~kg} \mathrm{~m}^{-2}$ over tropical convection areas, as well as in the mid-latitude storm tracks.

In the tropics, the difference appears relatively small compared to the all-sky value (i.e. around 10\% of dry bias), probably because clear-sky air mass is also warm and moist, not much different from cloudy-sky atmosphere. By contrast the dry bias of $3-5 \mathrm{~kg} \mathrm{~m}^{-2}$ over the mid-latitude storm tracks (Fig. 1a) corresponds to $30-50 \%$ of mean TPW there. The larger dry bias shown in the mid-latitude storm tracks is likely associated with the air mass difference during the 


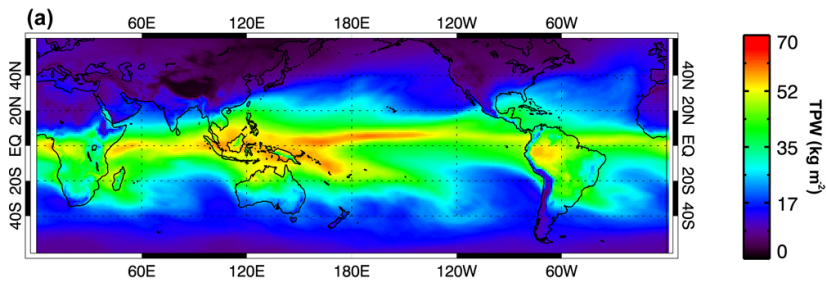

up to $10 \%$. Despite smaller differences in UTH of up to $+5 \%$, moist biases of UTH in cloud-free areas are found over subtropical subsidence regions, again due to the fact that the large-scale subsidence helps to develop low-level stratus-type clouds over the subtropical oceanic areas. In comparison to TPW, the stronger contrast of UTH bias between tropical convective regions and subtropical subsidence regions suggests that, in addition to the geographic distributions of UTH, differences between all-sky and cloud-free atmospheres are closely related to large-scale circulation over the tropics.

\section{Clear-sky flux influenced by the dry bias}
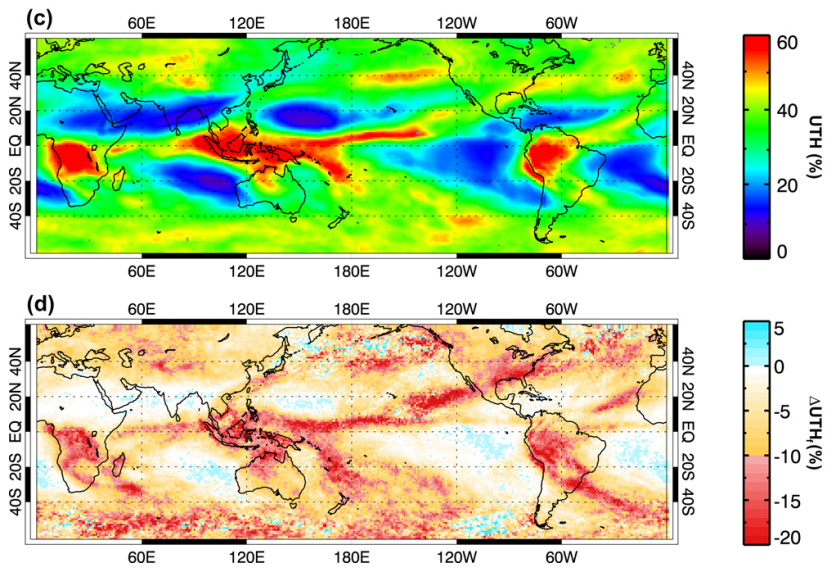

Because the CRF is determined by subtracting all-sky OLR from clear-sky OLR for the model (or cloud-free OLR for the satellite), the satellite-driven CRF effectively includes the longwave flux contributed by water vapor changes correlated with cloud presence. However, the model-generated CRF does not include the water vapor contribution correlated with cloud development. Here we quantify how much the clearsky flux is from a cloud-free atmospheric condition versus an all-sky atmospheric condition.

Beside water vapor difference between cloud-free atmosphere and all-sky atmosphere, the lapse rate difference may be another important parameter of influencing the clear-sky flux difference. However, changes in the lapse rate (here roughly defined as a mean temperature difference between two layers, i.e., surface $-500 \mathrm{hPa}$ and $500 \mathrm{hPa}-200 \mathrm{hPa}$ layers) from the cloud-free atmospheric conditions to the all-sky conditions is smaller than $0.5 \mathrm{~K}$ in absolute magnitude over the most of ocean regions (Fig. 2). Furthermore no particular patterns are noted in the difference, compared to the water vapor difference in Fig. 1. Mid-latitude storm tracks, however, are the areas showing differences up to $2 \mathrm{~K}$. Because of relatively small differences found over most of tropical oceans, we consider the impact of temperature difference on the clear-sky flux to be insignificant, and thus we interpret the OLR changes only in term of water vapor difference.

The clear-sky flux is determined from the atmospheric profiles at each radiation-time step (here every $5 \mathrm{~min}$ ) by assuming zero cloud cover for the radiative transfer calculation and thus should represent all-sky atmospheric conditions except for clouds. This clear-sky flux is shown in Fig. 3a, and the difference between the cloud-free flux and the clear-sky flux (henceforth referred to as $\Delta \mathrm{OLR}_{\mathrm{f}}$ ) is shown in Fig. 3b. As expected, due to the dry bias of the cloud-free atmosphere, the cloud-free flux results in more longwave emission over most of the oceans. Over the convectively active tropical areas, the difference is found to be larger than $7 \mathrm{Wm}^{-2}$, with a maximum of up to $10 \mathrm{Wm}^{-2}$ over the ITCZ in the equatorial Pacific, SPCZ, South African, and Amazonian rain forest areas.

The $\Delta \mathrm{UTH}_{\mathrm{f}}$ over tropical convective areas shows a dry bias greater than $20 \%$ in terms of precipitable water (PW), which is much larger than the maximum TPW fractional bias 

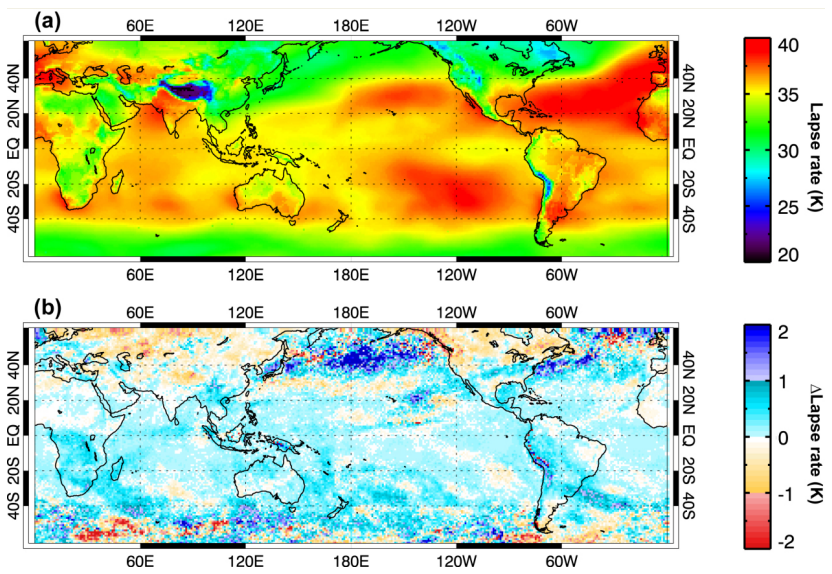

Fig. 2. Geographic distributions of one-month (15 December 200615 January 2007) means of (a) lapse rate and (b) lapse rate difference between cloud-free OLR and clear-sky OLR. The lapse rate is defined as the mean temperature difference between two layers (surface to $500 \mathrm{hPa}$ layer, and $500 \mathrm{hPa}$ to $200 \mathrm{hPa}$ layer).

In order to assess the degree of cloud forcing that can be attributed to the water vapor change associated with cloud development, a scatterplot of the NICAM model-generated CRF versus the $\triangle O \mathrm{OLR}_{\mathrm{f}}$ is shown (Fig. 4). For simplicity, we plot the relationship only over oceans within $30^{\circ} \mathrm{N}-30^{\circ} \mathrm{S}$ latitudes. The NICAM model simulations indicate that the water vapor effect on CRF tends to increase linearly with the increase of total CRF, and its contribution is about $10 \%$ of the total CRF. In other words, if NICAM simulations are perfect and thus representative of the real atmosphere, satellitederived CRF should be larger than model-generated CRF by about $10 \%$ because of the water vapor contribution added to satellite-estimated CRF.

In fact, observations indicate that CRF biases are likely larger than $10 \%$ of the total. Sohn et al. (2006) estimated the UTH bias of cloud-free atmosphere by combining the UTH from Special Sensor Microwave Temperature-2 Profiler brightness temperature with International Satellite Cloud Climatology Project (ISCCP) cloud data. It was shown that up to $12 \mathrm{Wm}^{-2}$, or about $15 \%$ of the satellite-derived longwave CRF in tropical regions, can be attributed to the UTH changes associated with cloud development. Considering that PW bias in the lower boundary layer is positively correlated with UTH bias, the resultant bias influence on the CRF is likely larger than the $15 \%$ of the total CRF. In summary, NICAM seems to underestimate the dry bias of the cloudfree atmosphere compared to what is expected from satellite measurements. Even so, it clearly demonstrates that there is an intrinsic conceptual difference between satellite-derived $\mathrm{CRF}$ and model-generated CRF and that the difference can be substantial.
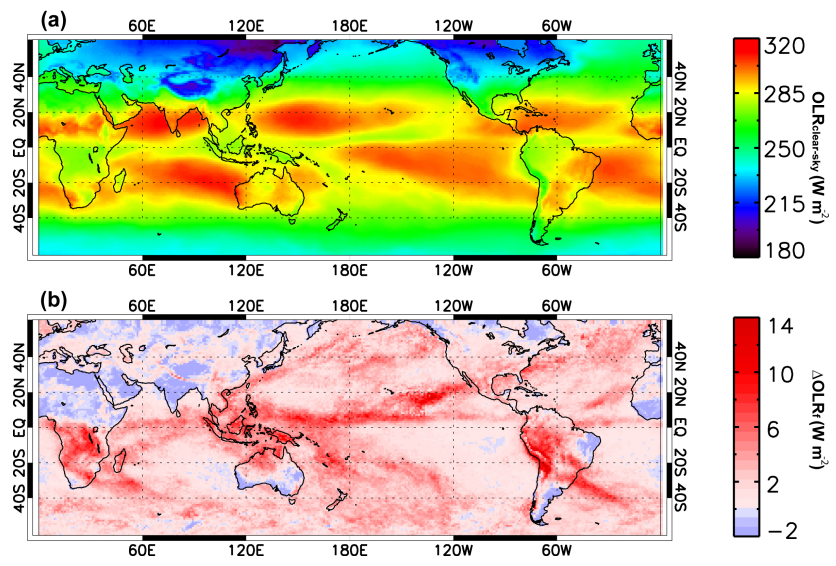

Fig. 3. Geographic distributions of one-month (15 December 200615 January 2007) means of (a) clear-sky OLR and (b) difference between cloud-free OLR and clear-sky OLR.

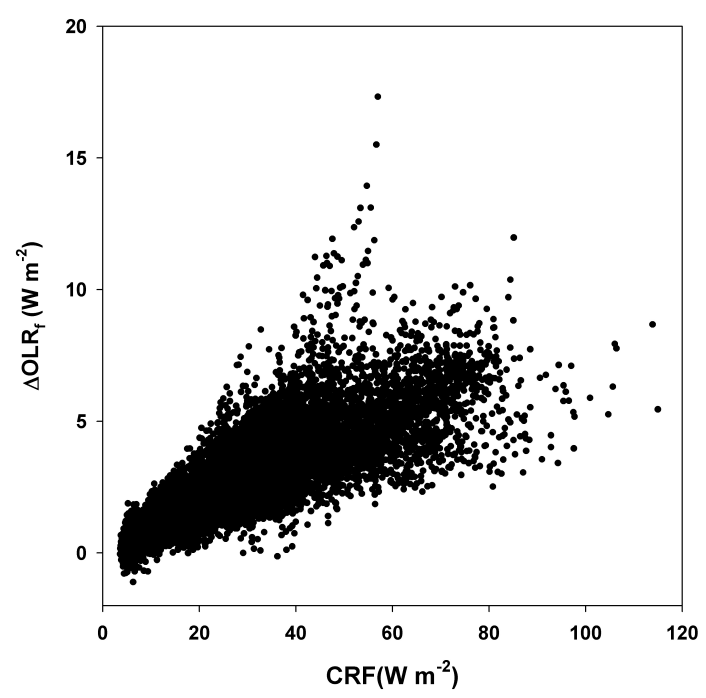

Fig. 4. Scatterplot of simulated longwave cloud radiative forcing and water vapor contribution to the longwave CRF.

\section{Summary and discussion}

The effect of using different definitions for clear-sky flux to calculate the longwave flux difference at the TOA, and thus CRF, was quantitatively examined. Using cloud-resolving NICAM global simulations from 15 December 2006-15 January 2007, two different clear-sky definitions (a cloud-free composite method versus a conventional clear-sky flux calculation method) were compared, and their impact on the determination of cloud forcing was examined.

Notably, water vapor distributions from the cloud-free composite (equivalent to the satellite method) showed consistent dry bias, except over cold ocean areas, when compared to the all-sky conditions used for the clear-sky flux calculation in the model. As expected, OLR fluxes taken 
from the cloud-free area were always higher than the clearsky fluxes derived from all-sky conditions. Differences larger than $5 \mathrm{Wm}^{-2}$ were found in most of the convectively active regions over the tropics and mid-latitude storm tracks. Because the CRF is determined by subtracting the measured total OLR from the clear-sky OLR, the longwave flux forced by water vapor changes correlated with cloud development is effectively included in the CRF when cloud-free flux is used. The CRF bias from the use of cloud-free flux amounts to about $10 \%$ of the total CRF.

The observation errors of monthly mean CERES longwave fluxes at the TOA are claimed to be around $1.7 \mathrm{Wm}^{-2}$ for a given region (Wielicki et al., 1995). However, the coarse resolution of CERES seems to induce additional error in the clear-sky flux because cloud-free scenes are determined from $10 \mathrm{~km}$ resolution pixels. A recent study of using highresolution MODIS data suggests that CERES clear-sky flux is overestimated by $0.3 \mathrm{Wm}^{-2}$ due to larger CERES footprints (Loeb et al., 2009). It was interpreted that differences in temperature and humidity near the cloud edge resolved by high-resolution Moderate Resolution Imaging Spectroradiometer (MODIS) measurements may induce decreased clear-sky flux. It is particularly true for UTH because UTH decreases rapidly within $50 \mathrm{~km}$ from the cloud edge (Udelhofen and Hartmann, 1995). Thus errors in CERES clearsky flux (or CRF) amount to $1.9 \pm 0.3 \mathrm{Wm}^{-2}$. If we take satellite-derived CRF as a representative, then CRF attributed by a dry bias of clear sky may be considered as an error of model-generated CRF. And the bias larger than $5 \mathrm{Wm}^{-2}$ over most of convective areas must be much higher than expected measurement error. Thus caution should be exercised when model-generated CRFs based on the conventional approach are compared with satellite measurements. In order to compare model-generated CRFs with satellite estimates in more consistent manner, the cloud-free composite method can be used with outputs from full resolution model, in conjunction with off-line radiative transfer calculations. Likewise results suggest that the near cancellation between longwave and shortwave cloud radiative forcing found in satellite measurements (e.g., Hartmann et al., 1992; Kiehl, 1994) should not be same in model simulations unless the cloud-free composite method is used.

Acknowledgements. Authors would like to thank two anonymous reviewers for their constructive and valuable comments which led to this improved version of the manuscript. This work was done while the first author stayed at CCSR, University of Tokyo, Japan, as a Visiting Professor. This work was supported by the Korea Meteorological Administration Research and Development Program under Grant CATER 2006-2103.

Edited by: J. Quaas

\section{References}

Allan, R. P. and Ringer, M. A.: Inconsistencies between satellite estimates of longwave cloud forcing and dynamical fields from reanalyses, Geophys. Res. Lett., 30(9), 1491, doi:10.1029/2003GL017019, 2003.

Barkstrom, B., Harrison, E., Smith, G., Green, R., Kibler, J., Cess, R., and the ERBE Science Team: Earth Radiation Budget Experiment (ERBE) archival and April 1985 results, B. Am. Meteorol. Soc., 70, 1254-1262, 1989.

Hartmann, D. L., Ockert-Bell, M. E., and Michelsen, M. L.: The effect of cloud type on Earth's energy balance: global analysis, J. Climate, 5, 1281-1304, 1992.

Kiehl, J. T.: On the observed near cancellation between longwave and shortwave cloud forcing in tropical regions, J. Climate, 7, 559-565, 1994.

Loeb, N. G., Wielicki, B. A., Doelling, D. R., Smith, G. L., Keyes, D. F., Kato, S., Manalo-Smith, N., and Wong, T.: Towards optimal closure of the Earth's top-of-atmosphere radiation budget, J. Climate, 22, 748-766, 2009.

Miura, H., Tomita, H., Nasuno, T., Iga, S., Satoh, M., and Matsuno, T.: A climate sensitivity test using a global cloud resolving model under an aqua planet condition, Geophys. Res. Lett., 32, L19717, doi:10.1029/2005GL023672, 2005.

Miura, H., Satoh, M., Nasuno, T., Noda, A. T., and Oouchi, K.: A Madden-Julian Oscillation event realistically simulated by a global cloud-resolving model, Science, 318, 1763-1765, 2007.

Ramanathan, V., Cess, R. D., Harrison, E. F., Minnis, P., Barkstrom, B. R., Ahmad, E., and Hartmann, D.: Cloud-radiative forcing and climate: Results from the Earth Radiation Budget Experiment, Science, 243, 57-63, 1989.

Roca, R., Louvet, S., Picon, L., and Desbois, M.: A study of convective systems, water vapor and top of the atmosphere cloud radiative forcing over the Indian Ocean using INSAT-1B and ERBE data, Meteorol. Atmos. Phys., 90, 49-65, doi:10.1007/s00703004-0098-3, 2005.

Satoh, M., Matsuno, T., Tomita, H., Miura, H., Nasuno, T., and Iga, S.: Nonhydrostatic Icosahedral Atmospheric Model (NICAM) for global cloud resolving simulations, J. Comp. Phys., 227, 3486-3514, 2008.

Slingo, A., Pamment, J. A., and Webb, M. J.: A 15-year simulation of the clear-sky greenhouse effect using the ECMWF reanalyses: Fluxes and comparisons with ERBE, J. Climate, 11, 690-708, 1998.

Sohn, B. J. and Bennartz, R.: Contribution of water vapor to observational estimates of longwave cloud radiative forcing, J. Geophys. Res., 113, D20107, doi:10.1029/2008JD010053, 2008.

Sohn, B. J. and Robertson, F. R.: Intercomparison of observed cloud radiative forcing: A zonal and global perspective, B. Am. Meteorol. Soc., 74, 997-1006, 1993.

Sohn, B. J., Schmetz, J., Stuhlmann, R., and Lee, J.-Y.: Dry bias in satellite-derived clear-sky water vapor and its contribution to longwave cloud radiative forcing, J. Clim., 19, 5570-5580, 2006.

Tomita, H. and Satoh, M.: A new dynamical framework of nonhydrostatic global model using the icosahedral grid, Fluid Dyn. Res., 34, 357-400, 2004.

Udelhofen, P. and Hartmann, D. L.: Influence of tropical convective cloud systems on the relative humidity in the upper troposphere, J. Geophys. Res., 100, 7423-7440, 1995. 
Wielicki, B. A., Cess, R. D., King, M. D., Randall, D. A., and Harrison, E. F.: Mission to planet Earth: Role of clouds and radiation in climate, B. Am. Meteor. Soc., 76, 2125-2153, 1995.
Wielicki, B. A., Barkstrom, B. R., Harrison, E. F., Lee, R. B., Smith, G. L., and Cooper, J. E.: Clouds and the Earth's Radiant Energy System (CERES): An Earth observing system experiment, B. Am. Meteorol. Soc., 77, 853-868, 1996. 